\title{
Measuring participation in people with spondyloarthritis using the social role participation questionnaire
}

\author{
Aileen M Davis, ${ }^{1,2,3,7}$ Marvilyn P Palaganas, ${ }^{1}$ Elizabeth M Badley, ${ }^{1,4}$ Dafna D Gladman, ${ }^{1,5}$ \\ Robert D Inman, 5,6 Monique A Gignac, ${ }^{1,4}$
}

- An additional table is published online only. To view this file please visit the journal online (http://ard.bmj.com)

${ }^{1}$ Division of Health Care and Outcomes Research, Toronto Western Research Institute, University Health Network, Toronto, Canada

${ }^{2}$ Department of Physical Therapy, University of Toronto, Toronto, Canada

${ }^{3}$ Department of Health Policy, Management and Evaluation, University of Toronto, Toronto, Canada

${ }^{4}$ Dalla Lana School of Public Health, University of Toronto,

Toronto, Canada

${ }^{5}$ Department of Medicine,

University of Toronto and

Toronto Western Hospital,

Toronto, Canada

${ }^{6}$ Division of Genetics and Development, Toronto Western Research Institute, University Health Network, Toronto,

Canada

${ }^{7}$ Department of Rehabilitation

Science, University of Toronto,

Toronto, Canada

\section{Correspondence to}

Aileen M Davis, Division of Health Care and Outcomes Research, Toronto Western Research Institute, 399 Bathurst Street, MP11-322, Toronto, Ontario M5T 2S8, Canada; adavis@uhnresearch.ca

Accepted 11 June 2011 Published Online First 25 July 2011

\begin{abstract}
Objectives People with spondyloarthritis (SpA), ankylosing spondylitis (AS) and psoriatic arthritis (PsA) have identified the importance of understanding how their disease and its treatment impacts on their social roles. This requires a reliable and valid standardised measure, and this study evaluates these measurement properties of the Social Role Participation Questionnaire (SRPO). Methods 109 participants (44 with AS, 65 with PsA) completed questionnaires on demographics, participation measures (SRPQ, Keele Assessment of Participation (KAP), Late Life Disability Instrument (LLDI)), disease severity (physician global) and activity (pain, fatigue, Bath Ankylosing Spondylitis Disease Activity Index), psychological measures (depressive symptoms (Hospital Anxiety and Depression Scale), Illness Intrusiveness)) and function (Health Assessment Questionnaire, Bath Ankylosing Spondylitis Functional Index). After testing scaling properties, test-retest reliability of the SRPO was evaluated using intraclass correlation coefficients (ICC) and hypotheses of construct validity were evaluated using correlation coefficients.
\end{abstract}

Results Patients with AS had a mean age of 40 years and $65 \%$ were male, whereas patients with PsA had a mean age of 53 years and $63 \%$ were male. Although there were some differences between AS and PsA participants in their social role participation, scaling properties were good for both groups. ICCs were $>0.90$ for the satisfaction subscales of the SRPQ. For construct validity, SRPQ satisfaction subscales were moderately correlated with the KAP and LLDI (0.64-0.78), and less satisfaction was associated with higher disease severity and activity, more depressive symptoms, more illness intrusiveness and more disability (coefficients -0.67 to $-0.88)$.

Conclusion Social role participation is an important concept for people with SpA, and the SRPQ is a reliable and valid measure for use with people with AS and PsA.

\section{INTRODUCTION}

The signs and symptoms of spondyloarthritis (SpA) - specifically ankylosing spondylitis (AS) and psoriatic arthritis (PsA)-frequently occur in the third to fifth decades of life ${ }^{1}$ when family, employment, social and leisure roles are prominent. Despite the saliency of these social roles and their relevance to health-related qualtiy of life (HRQoL), ${ }^{2}$ a limited literature describes individual aspects of role participation (eg, employment) in peaople with SpA. ${ }^{3-6}$ Role participation is important given that advances in the treatment of SpA with disease-modifying drugs (DMARDs) and biological agents have shifted the treatment paradigm from managing symptoms alone to slowing and potentially averting disease progression..$^{7-10}$ Yet longstanding disability that negatively impacts HRQoL continues for many individuals. ${ }^{11}{ }^{12}$ As such, evaluating the impact of interventions such as DMARDs and biological agents in maintaining or improving social role participation is critical to understanding their benefit. To date, no standardised measure has been used to evaluate social role participation in a comprehensive manner. ${ }^{2}$ This study addresses this gap, evaluating the measurement properties (content validity, reliability and construct validity) of the Social Role Participation Questionnaire (SRPQ) in people with SpA to determine if the questionnaire has suitable properties for use in future research studies to measure the impact of $\mathrm{SpA}$ on participation.

The World Health Organization's International Classification of Functioning, Disability and Health (ICF) defines participation as involvement in life situations. ${ }^{13}$ Such life situations or roles are broad patterns of purposeful behaviour at the level of societal involvement. ${ }^{14}$ They are expected, taught and encouraged within sociocultural contexts and are often undertaken because of a sense of personal value or necessity. ${ }^{15-17}$ They include involvement in close relationships (eg, parenting), being a student or employee and aspects of a person's identity related to social and leisure activities (eg, volunteer). These domains reflect broader life situations than those evaluated by activities of daily living. ${ }^{14}{ }^{18}$ Based on work using the ICF framework, people with AS reported mild or greater restriction in the domains of recreation and leisure, community life, remunerative employment, intimate relationships, informal social relationships, basic interpersonal interactions, family relationships, higher education, complex interpersonal interactions, formal relationships and assisting others. ${ }^{19}$ Similarly, people with PsA reported reduced ability to fulfil personal roles, limitations in their social life and work. ${ }^{20}$ Taylor et al similarly found that, while people with PsA experienced difficulties in many areas in the ICF domains of Activities and Participation, these domains mapped poorly to existing 'participation' and HRQoL measures that include subscales related to social functioning. ${ }^{21}$ The findings of Taylor et al confirmed previous work by Stamm et al. ${ }^{22}$

We chose to evaluate the SRPQ as it was conceptualised to include the domains of the ICF framework based on pilot work in people 
with osteoarthritis, work, psychosocial role research, existing participation measures and published arthritis studies. ${ }^{17}$ Additionally, in contrast to many existing standardised measures evaluating 'participation' that have focused on difficulty with or the frequency of performing specific tasks required for participation, ${ }^{14} 1823$ the SRPQ evaluates the importance of the role to the person and the perceived satisfaction with performing the various roles in the way desired and with the time spent in the role. ${ }^{17}$

\section{METHODS \\ Participants}

People with SpA were recruited from subspecialty clinics at the Toronto Western Hospital, Toronto, Canada. Participants ranged from those newly diagnosed to those with active or stable disease. Eligibility included age $\geq 18$ years, ability to complete English language questionnaires and consent to participate. Exclusion criteria included other musculoskeletal diseases (eg, fibromyalgia, a new fracture) or neurological diseases (eg, multiple sclerosis, stroke, Parkinson's disease) that might have an impact on participation. Of the 126 subjects eligible to participate, 109 consented and returned questionnaires (44 AS and 65 PsA). Patients with AS were younger, had shorter disease duration and were more likely to be engaged in educational pursuits (table 1).

\section{Procedures}

All participants completed demographic information (age, sex, living status, work status and current educational pursuits) and reported disease duration in addition to completing a battery of questionnaires described below.

To ensure content validity, understanding and clarity of the items, cognitive debriefing was conducted for the SRPQ with the first 15 participants. They also identified omissions of important roles and irrelevant content.

For test-retest reliability, a subsample completed the SRPQ 2-3 weeks after completing the first questionnaire. To ensure stability in the test period, respondents indicated if they felt their condition had changed in the interval.

\section{Measures}

Participation

The SRPQ includes 12 social role domains. ${ }^{17}$ Participants rated the importance of the role from 1 (not at all important) to 5 (extremely important) and their satisfaction each with time spent and their ability to participate in that role in the way they wanted (ie, role performance) from 1 (not at all satisfied) to 5 (extremely satisfied). If a respondent did not participate in a role they were instructed to choose 'not applicable' and did not provide an importance or satisfaction rating for that item. The mean score for each subscale was calculated providing at least nine of the 12 domains were answered.

Table 1 Description of participants

\begin{tabular}{lcc}
\hline & AS ( $\mathbf{n = 4 4 )}$ & PsA ( $\mathbf{n = 6 5 )}$ \\
\hline Male, $\mathrm{n}(\%)$ & $29(65.4 \%)$ & $41(63.2 \%)$ \\
Mean (SD) age, years & $39.9(13.0)$ & $52.7(11.0)$ \\
Mean (SD) disease duration, years & $8.6(8.2)$ & $16.6(1.2)$ \\
Total not working, $\mathrm{n}(\%)$ [due to disease] & $13(28.9 \%)[9]$ & $24(63.1 \%)[9]$ \\
Lives with others, $\mathrm{n}(\%)$ & $39(88.6 \%)$ & $51(78.5 \%)$ \\
In formal education, $\mathrm{n}(\%)$ & $10(22.7 \%)$ & $6(9.2 \%)$ \\
\hline
\end{tabular}

AS, ankylosing spondylitis; PsA, psoriatic arthritis.
The Keele Assessment of Participation (KAP) measures the occurrence of participation restriction in population samples. ${ }^{24}$ It includes 11 items across three areas (mobility, domestic life and major life), with responses on a 5-point scale (all the time to none of the time). We created a summed score based on achieving sufficient internal consistency (Cronbach's $\alpha^{25}$ for the 11 items was 0.81 and 0.89 for AS and PsA, respectively).

The Late Life Disability Instrument (LLDI) evaluates frequency and limitations in performing life tasks. ${ }^{26}$ Role domains and activities within each subscale are scored from 1 to 5 with higher scores indicating more frequent involvement and less limitation. Summed scores were calculated for each subscale.

\section{Disease severity}

For patients with PsA, the physician provided a global assessment of disease activity on a scale of $0-10$ where higher scores indicated more severe disease.

\section{Disease activity}

Participants with AS completed the Bath Ankylosing Spondylitis Disease Activity Index (BASDAI) which includes fatigue, spinal and peripheral joint pain, localised tenderness and severity and persistence of morning stiffness. ${ }^{27}$ Responses ranging from 0 to 10 were averaged, with higher scores indicating greater severity.

Participants with AS completed a numerical pain rating scale related to their back pain and those with PsA rated their current pain severity, both on a scale of $0-10$ where higher scores indicated more pain.

All participants completed the Fatigue Severity Scale, a measure of general fatigue that includes nine items asking about the severity and characteristics of fatigue in the past week. ${ }^{28}$ Response options range from 0 (not at all) to 10 (yes completely), and a summary score was computed based on the average of the item scores. $^{29}$

\section{Psychological}

Depressive symptoms were evaluated using the 7-item subscale of the Hospital Anxiety and Depression Scale (HADS). ${ }^{30}$ All items are scored on a 4-point scale from 0 to 3 , and higher scores indicate more depressive symptoms.

The 13-item Illness Intrusiveness Scale measures illnessinduced disruptions to activities, well-being and daily life. ${ }^{31} 32$ Response options range from not very much (1) to very much (7) and not applicable (99). The summary score is the sum of the individual items.

All participants completed the HADS and Illness Intrusiveness Scale.

\section{Function}

All completed the Health Assessment Questionnaire (HAQ), commonly used to report disability from arthritis. Participants respond on a scale from 0 (without any difficulty) to 3 (unable to do). ${ }^{33} 34$ The highest item score determines the value for each category and use of an aid or assistance results in a score increase. The average score across categories was calculated.

The Bath Ankylosing Spondylitis Functional Index has 10 questions asking about ability to do various activities in the past week. The scoring is $0-10$, as in the BASDAI. ${ }^{35}$

\section{Analysis of data}

Descriptive statistics were calculated for participant characteristics. Means and SDs were calculated for the individual items and subscales of the SRPQ. Scalability was evaluated by inter-item correlation coefficients where the desired range was $0.30-0.80$ to represent sufficient item associations without redundancy. 
Cronbach's $\alpha$ was calculated as a measure of homogeneity ${ }^{25}$ where the desired value was $\geq 0.80$.

Test-retest was calculated using the intraclass correlation coefficient (ICC) version 2,1. ${ }^{36} 37 \mathrm{~A}$ value of 0.90 was considered sufficient for individuals with at least 0.80 for groups. ${ }^{38}$ The standard error of measurement (SEM) based on the test-retest reliability coefficient and the minimal detectable change at the $95 \%$ confidence level $\left(\mathrm{MDC}_{95}\right)^{39} 40$ were calculated.

A priori hypotheses for testing construct validity were evaluated by correlational analyses using Pearson correlation ( $r$ ). Correlations $<0.4$ were considered weak, $0.4-0.70$ were moderate and $>0.70$ were considered strong. We hypothesised that the SRPQ satisfaction subscales would be moderately positively associated with measures of participation with content more focused on requisite tasks for participation. We also hypothesised that there would be a moderate inverse association between satisfaction subscales and disease severity, disease activity, depressive symptoms and illness intrusiveness, and function.

Furthermore, we anticipated that the SRPQ importance rating would be more highly correlated with satisfaction with time spent and role performance in older than younger individuals based on research on social networks, life course and successful ageing. This research suggests that older individuals voluntarily shrink their social network to include familiar and emotionally close partners whereas younger adults are more likely to choose novel social partners and activities. ${ }^{41}{ }^{42}$ As such, given the stage of life course, younger individuals would rate roles as more important but would experience less satisfaction with participation given the potential restrictions imparted by the morbidity of their disease.

Finally, we hypothesised that those who were not working due to their disease would report less satisfaction. This hypothesis was evaluated with the Wilcoxon test.

\section{RESULTS}

\section{Content validity and scaling of the SRPO}

Cognitive debriefing of the SRPO did not identify any items that were missing or unimportant and respondents thought the questionnaire was easily understood.

The range of response options was used for importance and the satisfaction importance of the different domains was similar for AS and PsA, with mean importance ranging from 1.4 to 3.6. Mean satisfaction ratings ranged from 1.3 to 3.3 and were similar for both time spent and role performance for both AS and PsA (online supplementary table). The inter-item correlations ranged from 0.09 to 0.75 for importance and from 0.36 to 0.89 for satisfaction with time spent and role performance for both AS and PsA (table 2). Cronbach's $\alpha$ for importance was 0.70 for patients with AS and 0.82 for those with PsA, compared with $\geq 0.93$ for the satisfaction subscales.

\section{Reliability of the SRPO}

Fifty-two participants (13 with AS, 39 with PsA) participated in test-retest reliability testing and reported no change over the 2 -week test period. The ICC for importance for PsA was sufficient for groups whereas it was sufficient for groups and individuals for AS (table 2). The satisfaction with time spent and role performance subscales had ICCs in excess of 0.90 for both AS and PsA participants, indicating reliability for both groups and individuals. The $\mathrm{MDC}_{95}$ ranged from 0.43 to 0.86 depending on the construct, with the values tending to be slightly larger for those with PsA.

\section{Construct validity}

Overall our a priori hypotheses were supported, demonstrating construct validity of the SRPQ (table 3). The SRPQ satisfaction subscales were moderately correlated (range 0.64-0.78) with other measures of participation (KAP and LLDI). For participants with AS the correlations of the SRPQ satisfaction subscales with the LLDI limitations subscale were slightly higher than anticipated at 0.76 and 0.78 .

Disease severity, disease activity, psychological and function measures had moderate associations with the satisfaction subscales of the SRPO, with a few exceptions (table 3). Fatigue had larger associations with satisfaction ranging from -0.72 to -0.80 for both AS and PsA, and illness intrusiveness had high correlations with satisfaction for AS (-0.88). Total back pain had small and nonsignificant correlations with satisfaction for those with AS.

As hypothesised, those who were work disabled because of their disease in both the AS and PsA groups reported lower satisfaction.

Finally, role importance was more highly associated with the satisfaction subscales for older people than for younger people for both the AS and PsA participants. For participants with PsA the correlation of importance with time spent and role performance was small and not significant in those aged $<40$ years. However, the magnitude of the correlation increased with age (50-59 years: range $0.40-0.50$; $\geq 60$ years: $0.70-0.75$ ). For participants with AS, there was no significant association for those aged 19-39 years and, for those 40-49 years, the correlations were 0.49 and 0.68 for importance with satisfaction with time spent and role performance, respectively.

\section{DISCUSSION}

This work shows that social role participation is an important concept for people with SpA and that the SRPQ is a reliable and valid measure for people with AS and PsA. The SRPQ incorporates the subjective aspects of participation, specifically an individual's desires and satisfaction. ${ }^{14}$ This is in contrast to other measures of participation ${ }^{26}$ that evaluate performance through frequency, limitation or role occupancy.

Table 2 Social Role Participation Questionnaire (SRPQ) subscale homogeneity and test-retest reliability coefficients

\begin{tabular}{|c|c|c|c|c|c|c|}
\hline & \multicolumn{3}{|l|}{ AS } & \multicolumn{3}{|l|}{ PsA } \\
\hline & Importance & $\begin{array}{l}\text { Satisfaction time } \\
\text { spent }\end{array}$ & $\begin{array}{l}\text { Satisfaction role } \\
\text { performance }\end{array}$ & Importance & $\begin{array}{l}\text { Satisfaction time } \\
\text { spent }\end{array}$ & $\begin{array}{l}\text { Satisfaction role } \\
\text { performance }\end{array}$ \\
\hline \multicolumn{7}{|c|}{ Scale homogeneity (AS: $n=44 ;$ PsA: $n=65$ ) } \\
\hline$\alpha$ & 0.69 & 0.96 & 0.95 & 0.82 & 0.93 & 0.93 \\
\hline \multicolumn{7}{|l|}{ Reliability (AS: $n=13 ; \operatorname{PsA}=39$ ) } \\
\hline Test-retest ICC (95\% CI) & 0.93 (0.70 to 0.98$)$ & 0.98 (0.93 to 0.99$)$ & $0.99(0.94$ to 0.99$)$ & $0.79(0.60$ to 0.90$)$ & 0.94 (0.88 to 0.97$)$ & 0.96 (0.92 to 0.98$)$ \\
\hline
\end{tabular}

$\alpha$, Cronbach's $\alpha$; AS, ankylosing spondylitis; ICC, intraclass correlation coefficient; $\mathrm{MDC}_{95^{\prime}}$ minimal detectable change at the $95 \%$ confidence level; PsA, psoriatic arthritis. 
Table 3 Results of construct validity testing of the importance and satisfaction with time spent and role performance subscales of the SRPQ ${ }^{\dagger}$ (Pearson correlation coefficients)

\begin{tabular}{|c|c|c|c|c|}
\hline & \multicolumn{2}{|c|}{ AS $(n=44)$} & \multicolumn{2}{|c|}{ PsA $(n=65)$} \\
\hline & $\begin{array}{l}\text { Satisfaction time } \\
\text { spent }\end{array}$ & $\begin{array}{l}\text { Satisfaction role } \\
\text { performance }\end{array}$ & $\begin{array}{l}\text { Satisfaction time } \\
\text { spent }\end{array}$ & $\begin{array}{l}\text { Satisfaction role } \\
\text { performance }\end{array}$ \\
\hline \multicolumn{5}{|l|}{ Participation } \\
\hline $\mathrm{KAP}^{\dagger}$ & 0.72 & 0.68 & 0.68 & 0.65 \\
\hline \multicolumn{5}{|l|}{$\operatorname{LLDI}^{\dagger}$} \\
\hline Frequency & 0.67 & 0.64 & 0.67 & 0.64 \\
\hline Limitations & 0.76 & 0.78 & 0.65 & 0.66 \\
\hline \multicolumn{5}{|l|}{ Disease severity } \\
\hline $\begin{array}{l}\text { Physician Global Disease } \\
\text { Activity (PsA) }\end{array}$ & & & -0.41 & -0.40 \\
\hline \multicolumn{5}{|l|}{ Disease activity } \\
\hline BASDAI score (AS) & -0.45 & -0.48 & & \\
\hline Total back pain (AS) & $-0.22^{*}$ & $-0.19^{*}$ & & \\
\hline Pain severity (PsA) & & & -0.40 & -0.37 \\
\hline Fatigue & -0.77 & -0.80 & -0.72 & -0.77 \\
\hline \multicolumn{5}{|l|}{ Psychological } \\
\hline Depression & -0.69 & -0.69 & -0.67 & -0.70 \\
\hline IIIness intrusiveness & -0.88 & -0.88 & -0.67 & -0.68 \\
\hline \multicolumn{5}{|l|}{ Function } \\
\hline HAO & -0.72 & -0.68 & -0.57 & -0.57 \\
\hline BASFI score (AS) & -0.72 & -0.73 & & \\
\hline
\end{tabular}

${ }^{*}$ Correlation is not statistically significantly different from zero.

${ }^{\dagger}$ Higher scores indicate higher levels of the construct (ie, more satisfaction, more frequency of participation etc). For all other measures, higher scores indicate more problems.

AS, ankylosing spondylitis; BASDAI, Bath Ankylosing Spondylitis Disease Activity Index; BASFI, Bath Ankylosing Spondylitis Functional Index; HAQ, Health Assessment Questionnaire; KAP, Keele Assessment of Participations; LLDI, Late Life Disability Index; PsA, psoriatic arthritis.

The content validity of the SRPQ was supported by the cognitive debriefing process in this research, as well as by work of others evaluating individual aspects of participation. Ward et al found that family life and participation in the labour force were affected in people with AS. ${ }^{5}$ Additionally, people with AS were more likely never to marry and, if married, were less likely to have children and more likely to be divorced. Boonen et al also reported work disability in people with $\mathrm{AS}^{3}{ }^{4}$ and Wallenius et al reported work disability in people with PsA aged 19-40 years. ${ }^{6}$ Finally, the domains included in the SRPQ reflect common problems experienced by people with $\mathrm{AS}^{19}$ and PsA. ${ }^{21}$

The SRPQ items represent concepts of social roles (eg, physical leisure) rather then specific pursuits within a role (eg, gardening). Although there is diversity in the range of roles captured, the inter-item correlations and internal consistency showed that each of the satisfaction subscales (satisfaction with time spent in roles and satisfaction with role performance) represented a unified concept. The importance ratings demonstrated lower internal consistency than the satisfaction ratings. We interpret the variability in response and lower internal consistency to reflect the different choices and preferences people have for the many social roles in which they participate. Work that describes obligatory and discretionary activities and roles supports our interpretation. ${ }^{14} 4344$

The test-retest reliability levels of the SRPQ subscales are sufficient for groups and individuals (ie, $>0.90$ ), with the exception of the importance subscale for PsA. ${ }^{38}$

Evaluation of construct validity was guided by findings from the existing literature, recognising that most authors evaluated a specific aspect of participation. With few exceptions, we were able to confirm our hypotheses. The $\mathrm{LLDI}^{26}$ and $\mathrm{KAP}^{24}$ include a number of items that are more task-orientated and they had moderate correlations (0.40-0.70) with the SRPQ satisfaction subscales. The exception was in AS where the correlations were 0.76 and 0.78 . While these relationships were slightly higher than expected, only about $60 \%$ of the variance in satisfaction is explained. Our findings that more disease severity and activity, psychological impact and functional limitations were associated with less satisfaction in participation similarly is supported by the literature. ${ }^{17}{ }^{45-47}$ For example, in people with AS, Healey et al found that poor function, depression, increased disease activity, unemployment and poor self-efficacy were independently associated with more problems in sexual relationships. ${ }^{45}$ In people with $\mathrm{SpA}, \mathrm{Da}$ Costa et al found that mental health status and leisure time activity were associated with fatigue and that mental health moderated the relationship between leisure time activity and fatigue-that is, leisure activity was associated with decreased fatigue in those with good mental health. ${ }^{46}$

Similar to our findings that older people were most satisfied with their participation in social roles, Healey et al found that younger people with AS (18-49 years) reported a greater impact on their relationships than those aged $\geq 65$ years. ${ }^{45}$ Dagfinrud et al similarly found that the impact of AS decreased with age. ${ }^{48}$

Work disability has been reported in AS and $\mathrm{PsA}^{3-5}$ and, although the number not working because of their disease was small, we found that, as hypothesised, those who were work disabled were less satisfied with their participation.

Most surprising was the finding that back pain in people with AS was not significantly associated with any of the SRPQ subscales. We anticipated that these correlations would be modest given other literature that suggests that pain is moderately associated with physical disability and that disability mediates the relationship between pain and participation. ${ }^{47}$ The correlations with the satisfaction subscales were -0.19 and -0.22 . However, as our sample included only 44 participants with AS, our findings may reflect a $\beta$ error. ${ }^{49}$

This work includes a clinical sample from a single institution which may limit its generalisability. However, the participants 
with AS and PsA are comparable to those reported in the literature based on demographics, disease severity and disability. The PsA group included a slightly higher proportion of men. In addition, as the questionnaires required fluency in English, cultural differences may not have been captured. The SRPQ, as with other participation measures, has been developed in English and there may be interesting differences in perceived role importance and participation in relation to culture. Furthermore, while the content of the measure was developed from several sources ${ }^{17}$ and confirmed in the current participants, future work prior to use in other countries should confirm that the content is relevant and that there are no omissions.

In summary, the SRPQ is a reliable and valid measure of social role participation in people with SpA that can be used to evaluate the complex inter-relationships of symptoms, disability and participation, and the personal and environmental contextual factors that influence participation itself and these relationships. Longitudinal studies will enhance our understanding of the impact of disease on participation over the life course as people evolve their social roles. Finally, further research needs to evaluate the responsiveness of the SRPQ subscales in response to interventions so that we can further understand their impact on people's participation.

Funding This work was supported by a National Research Initiative grant from The Arthritis Society awarded to the Spondyloarthritis Research Consortium of Canada.

Ethics approval This study was conducted with the approval of the research ethics board, University Health Network.

Provenance and peer review Not commissioned; externally peer reviewed.

\section{REFERENCES}

1. Gabriel SE, Michaud K. Epidemiological studies in incidence, prevalence, mortality, and comorbidity of the rheumatic diseases. Arthritis Res Ther 2009;11:229.

2. Davis AM, Wong R, Badley EM, et al. There's more to life than everyday function: the challenge of measuring social role participation in ankylosing spondylitis. Nat Clin Pract Rheumatol 2009;5:46-51.

3. Boonen A, de Vet $\mathrm{H}$, van der Heijde D, et al. Work status and its determinants among patients with ankylosing spondylitis. A systematic literature review. J Rheumatol 2001;28:1056-62.

4. Boonen A. A review of work-participation, cost-of-illness and cost-effectiveness studies in ankylosing spondylitis. Nat Clin Pract Rheumatol 2006;2:546-53.

5. Ward MM, Reveille JD, Learch TJ, et al. Impact of ankylosing spondylitis on work and family life: comparisons with the US population. Arthritis Rheum 2008;59:497-503.

6. Wallenius M, Skomsvoll JF, Koldingsnes W, et al. Work disability and healthrelated quality of life in males and females with psoriatic arthritis. Ann Rheum Dis 2009;68:685-9.

7. Braun J, Baraliakos X. Treatment of ankylosing spondylitis and other spondyloarthritides. Curr Opin Rheumatol 2009;21:324-34.

8. Gladman DD. Psoriatic arthritis. Dermatol Ther 2009;22:40-55.

9. Saber TP, Veale DJ. Psoriatic arthritis management update - biotherapeutic options. J Rheumatol Supp/ 2009;83:65-8.

10. Rozenblit M, Lebwohl M. New biologics for psoriasis and psoriatic arthritis. Dermatol Ther 2009;22:56-60.

11. Gladman DD. Disability and quality of life considerations. Psoriatic arthritis. In: Gordon GB, Ruderman E, eds. Psoriasis and Psoriatic Arthritis: An Integrated Approach. Heidelberg: Springer-Verlag 2005:118-23.

12. Rohekar S, Pope J. Assessment of work disability in seronegative spondyloarthritis. Clin Exp Rheumatol 2010;28:35-40.

13. World Health Organization. International Classification of Functioning, Disability and Health. Geneva: World Health Organization, 2001.

14. Dijkers MP. Issues in the conceptualization and measurement of participation: an overview. Arch Phys Med Rehabil 2010;91 (9 Suppl):S5-16.

15. Reber AS. The Penguin Dictionary of Psychology. London: Penguin Books 1985

16. Thoits PA. Social support as coping assistance. J Consult Clin Psychol 1986;54:416-23

17. Gignac MA, Backman CL, Davis AM, et al. Understanding social role participation: what matters to people with arthritis? J Rheumatol 2008;35:1655-36.

18. Magasi S, Post MW. A comparative review of contemporary participation measures' psychometric properties and content coverage. Arch Phys Med Rehabil 2010;91(9 Suppl):S17-28.
19. van Echteld I, Cieza A, Boonen A, et al. Identification of the most common problems by patients with ankylosing spondylitis using the international classification of functioning, disability and health. J Rheumatol 2006;33:2475-83.

20. McKenna SP, Doward LC, Whalley D, et al. Development of the PsAOoL: a quality of life instrument specific to psoriatic arthritis. Ann Rheum Dis 2004;63:162-9.

21. Taylor WJ, Mease PJ, Adebajo A, et al. Effect of psoriatic arthritis according to the affected categories of the international classification of functioning, disability and health. J Rheumato/ 2010;37:1885-91.

22. Stamm TA, Nell V, Mathis $M$, et al. Concepts important to patients with psoriatic arthritis are not adequately covered by standard measures of functioning. Arthritis Rheum 2007:57:487-94.

23. Badley EM. Enhancing the conceptual clarity of the activity and participation components of the International Classification of Functioning, Disability, and Health. Soc Sci Med 2008;66:2335-45.

24. Wilkie R, Peat G, Thomas E, et al. The Keele Assessment of Participation: a new instrument to measure participation restriction in population studies. Combined qualitative and quantitative examination of its psychometric properties. Qual Life Res 2005;14:1889-99.

25. Chronbach L. Coefficient alpha and the internal structure of tests. Psychometrika 1951;16:297-334

26. Jette AM, Haley SM, Coster WJ, et al. Late life function and disability instrument: I. Development and evaluation of the disability component. J Gerontol A Biol Sci Med Sci 2002; 57:M209-16

27. Garrett S, Jenkinson T, Kennedy LG, et al. A new approach to defining disease status in ankylosing spondylitis: the Bath Ankylosing Spondylitis Disease Activity Index. J Rheumatol 1994;21:2286-91.

28. Krupp LB, LaRocca NG, Muir-Nash J, et al. The fatigue severity scale. Application to patients with multiple sclerosis and systemic lupus erythematosus. Arch Neurol 1989;46:1121-3.

29. Neuberger GB. Measures of fatigue: the Fatigue Questionnaire, Fatigue Severity Scale, Multidimensional Assessment of Fatigue Scale, and Short Form-36 Vitality (Energy/ Fatigue) Subscale for the Short Form Health Survey. Arthritis Rheum 2003;49:S175-83.

30. Zigmond AS, Snaith RP. The hospital anxiety and depression scale. Acta Psychiatr Scand 1983:67:361-70.

31. Devins GM. Ilness intrusiveness and the psychosocial impact of lifestyle disruptions in chronic life-threatening disease. Adv Ren Replace Ther 1994;1:251-63.

32. Devins GM, Dion R, Pelletier LG, et al. Structure of lifestyle disruptions in chronic disease: a confirmatory factor analysis of the IIIness Intrusiveness Ratings Scale. Med Care 2001;39:1097-104.

33. Fries JF, Spitz P, Kraines RG, et al. Measurement of patient outcome in arthritis. Arthritis Rheum 1980;23:137-45.

34. Fries JF, Spitz PW, Young DY. The dimensions of health outcomes: the health assessment questionnaire, disability and pain scales. J Rheumatol 1982;9:789-93.

35. Calin A, Garrett $\mathrm{S}$, Whitelock $\mathrm{H}$, et al. A new approach to defining functional ability in ankylosing spondylitis: the development of the Bath Ankylosing Spondylitis Functional Index. J Rheumatol 1994;21:2281-5.

36. Shrout $\mathbf{P E}$, Fleiss JL. Intraclass correlations: uses in assessing rater reliability. Psychol Bull 1979;86:420-8.

37. Portney LG, Watkins MP. Foundation of Clinical Research: Applications to Practice. Second edn. Norwich, Connecticut: Appleton and Lange, 2000:557-86.

38. Nunnally J. Psychometric Theory. Second edn. New York, NY: Oxford University Press, 1978.

39. Lassere MN, van der Heijde D, Johnson K, et al. Robustness and generalizability of smallest detectable difference in radiological progression. J Rheumatol 2001;28:911-13.

40. Beaton DE. Understanding the relevance of measured change through studies of responsiveness. Spine 2000;25:3192-9.

41. Fredrickson BL, Carstensen LL. Choosing social partners: how old age and anticipated endings make people more selective. Psychol Aging 1990;5:335-47.

42. Fung HH, Carstensen LL, Lang FR. Age-related patterns in social networks among European Americans and African Americans: implications for socioemotional selectivity across the life span. Int J Aging Hum Dev 2001;52:185-206.

43. Verbrugge L. The iceberg of disability. In: Stahl SM, ed. Longevity: Health and Health Care in Later Life. Newbury Park, CA: Sage Publications, 1990:55-75.

44. Katz $\mathbf{P}$, Morris A. Time use patterns among women with rheumatoid arthritis: association with functional limitations and psychological status. Rheumatology (Oxford) 2007;46:490-5.

45. Healey EL, Haywood KL, Jordan KP, et al. Ankylosing spondylitis and its impact on sexual relationships. Rheumatology (Oxford) 2009;48:1378-81.

46. Da Costa D, Dritsa M, Ring A, et al. Mental health status and leisure-time physical activity contribute to fatigue intensity in patients with spondylarthropathy. Arthritis Rheum 2004;51:1004-8.

47. Machado GP, Gignac MA, Badley EM. Participation restrictions among older adults with osteoarthritis: a mediated model of physical symptoms, activity limitations, and depression. Arthritis Rheum 2008;59:129-35.

48. Dagfinrud $\mathbf{H}$, Mengshoel AM, Hagen KB, et al. Health status of patients with ankylosing spondylitis: a comparison with the general population. Ann Rheum Dis 2004:63:1605-10.

49. Cohen J. Statistical Power Analysis for the Social Sciences. Second edn. Hillsdale, New Jersey: Lawrence Erlbaum Associates, 1988. 


\section{ARD}

\section{Measuring participation in people with spondyloarthritis using the social role participation questionnaire}

Aileen M Davis, Marvilyn P Palaganas, Elizabeth M Badley, et al.

Ann Rheum Dis 2011 70: 1765-1769 originally published online July 25, 2011

doi: 10.1136/ard.2010.149211

Updated information and services can be found at:

http://ard.bmj.com/content/70/10/1765.full.html

These include:

Data Supplement

"Web Only Data"

http://ard.bmj.com/content/suppl/2011/06/24/ard.2010.149211.DC1.html

References This article cites 42 articles, 13 of which can be accessed free at: http://ard.bmj.com/content/70/10/1765.full.html\#ref-list-1

Email alerting Receive free email alerts when new articles cite this article. Sign up in service the box at the top right corner of the online article.

Topic Articles on similar topics can be found in the following collections Collections

Ankylosing spondylitis (252 articles)

Calcium and bone (451 articles)

Connective tissue disease (2464 articles)

Degenerative joint disease (2713 articles)

Immunology (including allergy) (2875 articles)

Musculoskeletal syndromes (2920 articles)

Rheumatoid arthritis (1862 articles)

Pain (neurology) (619 articles)

Notes

To request permissions go to:

http://group.bmj.com/group/rights-licensing/permissions

To order reprints go to:

http://journals.bmj.com/cgi/reprintform

To subscribe to BMJ go to:

http://group.bmj.com/subscribe/ 